\title{
Women's experiences of intimate partner violence in rural Taranaki, Aotearoa New Zealand
}

Lesley Pitt ${ }^{1}$, Jane Maidment ${ }^{2}$ and Yvonne Crichton-Hill ${ }^{2}$

\begin{abstract}
INTRODUCTION: Traditionally, research about intimate partner violence has focused on urban areas and has been urban-centric. However, there are some components of intimate partner violence in rural communities which are different and social workers need to be aware of these variances.
\end{abstract}

METHODS: The findings presented in this article were drawn from a doctoral study in which 23 women and five men were interviewed using a qualitative approach. Alongside these interviews, key informants in the rural Taranaki district were consulted, a fieldwork journal kept and photographs taken. The data were analysed using applied thematic analysis.

FINDINGS: Patriarchy was a distinct aspect of the intimate partner violence experienced by the women who participated in this study and part of the back-drop to their lives. Hegemonic masculinity was a powerful contributor to the intimate partner violence experienced by some study participants. Geographic isolation was exploited as an aspect of control in intimate partner violence among the women, and women had difficulty accessing services.

CONCLUSION: It is important for social workers, in order to practise competently, to have an awareness of the impact of patriarchy and hegemonic masculinity. When working in rural communities, social workers need to be attentive to the factors which impact on rural women who have experienced intimate partner violence, and how these factors might differ from those that impact urban women's experiences.

KEYWORDS: rural; intimate partner violence; patriarchy; hegemonic masculinity

This article presents findings drawn from doctoral research about the lived experience of poverty in rural Taranaki in Aotearoa New Zealand. The broader study explored the impact of poverty in a rural Taranaki district. Research questions which underpinned the inquiry explored the impact of poverty on participants' lives, how the participants coped day to day and what the implications of this were for social work with the poor in rural communities. Although the study did not set out to explore intimate partner violence it was uncovered as an aspect of some participants' experience of daily living in poverty.

Most recently, there has been some research activity about intimate partner violence in rural communities (Faber \& Miller-Cribbs, 2014; Hall-Sanchez, 2016; Little, 2017; Mason, 2012; Rennison \& DeKeseredy, 2017; Wendt, 2009; Wendt, Chung, Elder, Hendrick, \& Hartwig, 2017; Wendt \& Zannettino, 2015),
1 Open Polytechnic of New Zealand

${ }^{2}$ University of Canterbury
AOTEAROA NEW ZEALAND SOCIAL WORK 31(1), 31-41.

CORRESPONDENCE TO: Lesley Pitt lesley.pitt@ openpolytechnic.ac.nz 
however, in Aotearoa New Zealand, research about this topic has been limited. While rates of violence are similar between rural and urban areas, there are some aspects of rural intimate partner violence which are different from that experienced by urban women. Violence in rural localities can be exacerbated by geographic isolation, the presence of, and easy access to, firearms, a patriarchal culture with more defined gender roles than those found in urban areas and women being coerced to keep private what goes on within their homes (Wendt \& Zannettino, 2015). Pressure to keep secrets may be more pronounced in rural communities where people are interconnected through family relationships and social activities and privacy is carefully protected (Little, 2017). Help can be difficult to access due to a lack of rural social and legal services and/or poorly funded and understaffed social services. Slow response times of emergency services as a result of distance and low staffing numbers in rural locations add to the obstacles to help seeking, which can be compounded when women lack transport (Edwards, Mattingly, Dixon, \& Banyard, 2014; Faber \& MillerCribbs, 2014; Mason, 2012; Wendt, 2009; Wendt et al., 2017). Participants in this study who talked about intimate partner violence identified that being poor and living in a rural location made it challenging to leave their relationships and to get support and information.

The term intimate partner violence was chosen in this study as it accurately described the violence which takes place when people are in a relationship of an intimate nature (Crichton-Hill \& Taylor, 2013). There are other terms used in literature and within social services such as domestic violence or family violence, however, these terms include more than violence within an intimate relationship. Domestic violence has been used to describe violence between intimate partners, however the word domestic indicates something wider than violence within intimate adult relationships. Family violence is also a term commonly used in social policy and social services, but like the term domestic violence is a descriptor which includes a range of people considered to be within a family system. Intimate partner violence, while gender neutral, is more accurate in describing violence by an intimate male partner towards a woman (Crichton-Hill \& Taylor, 2013) which is supported by a wider system of patriarchal social relations (Bryson, 1992; hooks, 1982; Millett, 1971).

An area where different definitions of intimate partner violence create confusion is with the use of statistics (Crichton-Hill \& Taylor, 2013). Police statistics for the study area were collected for family violence, not intimate partner violence. The study district falls into the Central District policing area which covers Taranaki, Whanganui-Ruapehu and Manawatu provinces. In 2016 there were 11,788 family violence investigations carried out by the police in the Central District area (New Zealand Family Violence Clearinghouse, 2017). Statistics are not available for the study district specifically although it is estimated that, during 2017, 2,500 police call-outs related to family violence in the rural Taranaki police area which includes the study district and South Taranaki (S. Howard, Police Projects Leader, personal communication, 27 April, 2018). These statistics give a general indication about the rate of intimate partner violence in the district but are not specifically defined as intimate partner violence. Women's Refuge report that, nationally, 1,059 women and children living in "isolated rural areas" (Women's Refuge, 2015, p. 24) received assistance from their services.

\section{Methods}

The majority of participants in this research lived in a rural district in the Taranaki province which has one small town which is the service area for the surrounding farming community. This district was chosen as it was accessible for data gathering and represented a rural community which had a range of rural economic activity; dairy 
farming, sheep and beef farming and forestry. The data were gathered using four approaches. Qualitative interviews, which were recorded and then transcribed, were carried out. A field work journal was kept and used as part of the data analysis. Key informants, who had some experience working with the poor in the district, were consulted and asked to assist in recruitment. Lastly, photographs were taken of the study area. None of the photographs used as part of the data collection included participants or potential identifiers of participants.

A total of 28 participants (23 women and five men) were interviewed for the study; three interviews were carried out with couples and the remainder of interviews were with individuals. Violence was not discussed during the interviews with couples and the decision to be interviewed together was the choice of participants. New Zealand Europeans made up 22 of the participants, while there were four Māori, one British and one participant was from Africa. Statistics New Zealand (n.d.) drawing on data from the 2013 census identified that $91.8 \%$ of the district area of the study identify themselves as New Zealand European, a higher proportion than the national average. The youngest participant in the study was 17 and the oldest was over 70. A total of 22 participants were on a benefit, including National Superannuation, and the remaining six were either employed or their partner was. Participants self-identified as poor rather than a particular definition of poverty being imposed on them which could be experienced as stigmatising.

As the rural poor could be considered a hard to reach population (Mammen \& Sano, 2012), intermediaries (and key informants mentioned above), social workers and other social service workers were used in recruitment. Intermediaries gave potential participants information sheets about the study and, if the potential participant was interested in being interviewed, their contact details were supplied to the researcher. Wherever possible initial contact was made with prospective participants by text message; this enabled them to ignore the text if they no longer wanted to participate in the study. While the use of intermediaries proved useful in making contact with some participants it did not generate the numbers needed for an adequate sample, consequently snowballing was used. Snowballing is an approach which has been identified as effective in accessing hard to reach populations (Sadler, Lee, Lim, \& Fullerton, 2010). A snowballing approach engaged participants in recommending further participants through their contacts (Babbie, 2017; Davidson \& Tolich, 2003; May, 2011). Each participant was provided with copies of the information sheet at the end of their interview and asked to give the information sheets to people they knew who met the criteria of the study, and who they considered might be interested in participating. Participants identified through the snowballing approach stated they had been told the interviewer was easy to talk to, thus trust in the process was enhanced.

Participants in this research were marginalised due to their economic position hence every care was taken to protect their needs and maintain high ethical standards. Ethical approval for this study was granted by the Human Ethics Committee of the University of Canterbury on 26 March 2015. As part of the ethics approval process at the University of Canterbury, the research proposal was approved by the Māori Research Advisory Group of the University of Canterbury Human Ethics Committee on the 22 January 2015.

Applied thematic analysis was used to analyse the data which included the interviews with participants and key informants and fieldwork journal notes. The photographs have been used to support the findings. A code book was developed in which preliminary codes were identified and these were defined and then refined throughout the data analysis (Crabtree \& Miller, 1992). The interview recordings were listened to and then mind maps created for 
each interview as a way to tease out potential codes. Data were then read closely, and notes taken in the margins of the scripts, making links between the text and the codes. The codes were used to organise the data in the software program, NVivo. From the initial codes wider themes were identified (Guest, MacQueen, \& Namey, 2012).

\section{Findings}

\section{Patriarchy}

The presence of patriarchy within family systems was a theme in this study.

Patriarchy describes a system in which men dominate women (hooks, 1982) and also men are dominated by other men (Averett, 2009; Millett, 1971; Pease, 2016). Participants talked in interviews about how gender had shaped their lives in both the private sphere of home and family and the public world of work. Patriarchy was evident in the private sphere for Sally who talked about the control her ex-partner exerted over her when their relationship ended.

Sally: That's pretty much why we split up, because after a year, I figured there was no trust at all. There was just rules, controlling. And then [after they separated] he made me feel bad for not going to his job and not doing his calves [feeding]. But it's hard, because my mum and her boyfriend, they love Jack [ex-partner]. They still go fishing with Jack and go to golf with him. When I did leave, I got the, "I need your help," "I'm going to kill myself," "I feel like I can't do this without you," "“I can't do this by myself." So I'd go back. Then I went out to a party and asked Jack to pick me up. He was at home watching Braden [son] and he picks me up 10 times drunker than I was and was being an idiot with his car. So I'd leave again, cos I'm more grown up than that, I guess.

Sally described, as part of intimate partner violence, hegemonic masculinity, where normalised ways of behaving for men included heavy drinking. In Sally's instance, Jack had more access to power than her through his employment and relationship with her family (Jewkes et al., 2015). Jack was better off financially than Sally post-separation as he maintained his employment and home on the farm, and he was able to garner support from Sally's family despite his abusive behaviour. The gender roles in relation to farm work described by Sally, where she fed calves, is an example of the traditional division of labour in rural settings where it is assumed women will care for young animals. These gender roles in rural communities leave women constrained in relation to the nature of the farm work they can carry out and limits their development of skills and potential future employment.

Like Sally, Lisa talked about the power her partner exerted over her and the way he controlled her with threats of violence. Control has been identified as one of the key features of patriarchy (Bryson, 1992; Whelehan, 1995). In Lisa's case, as for Sally, her partner used his male privilege, his power as a man to dominate her.

Lisa: And then, once I was back there, that was something he had over me. It was like "This is my house now, and you're here because I said you could come back" and all the arguments. He was like, "Pack your bags and fuck off." "I'll chop you up and throw you down the driveway," and all this horrible stuff.

Sally and Lisa talked about male privilege, the assumption of entitlement by men (Connell, 1995; Pease, 2016), within their relationships. A culture of male entitlement was also identified in a South Australian study as an aspect of rural intimate partner violence (Wendt \& Zannettino, 2015).

While Sally and Lisa talked about patriarchy within their relationships, Megan described how wider social and legal systems support male power, in her case, the Family Court system. Megan did not want to live in the district but was ordered to stay in the area by a Family Court Judge, as she described in her interview. 
Megan: Him [father of her child] and his partner bought a house in [the study district] about nine months ago, I think it was, and the Judge thought... To me I didn't feel like I had any choice, because it felt like the Judge was actually ruling in my ex's favour and the stupid thing for this is they brought in an outside Judge. They brought in a Nelson judge who obviously didn't know Taranaki and the area at all. And even me trying to explain that my ex worked in a town 20 minutes drive away so it's not like he was going out of his way to pick up his son on the weekly routine we had. The Judge put it down to, oh my lack of transport, something else, something else and something else and he goes, "Oh I suggest you guys work this out between you." He wasn't actually in my favour at all. It was all to do with Luke [ex-partner] and honestly, I found it sexist, because he was a male Judge and he was looking at Luke like he was God's gift to man and quite frankly, he's a fuckwit and I could punch him in the face if I could... But I won't say anything like that to my son because that's just rude and mean and he doesn't need to know that - he can make his own choices when he's older.

For Megan, the ruling in favour of her expartner left her in a powerless position as her partner's needs were given precedence over hers. Megan's poverty and lack of transport made her situation worse. She wanted to move to New Plymouth (only city in the province) to obtain work but was not able to do so because of the court ruling. Being aware of the way power is used against clients is an important part of social work practice. For Megan, a participant in this study discussed earlier in the article, having support and advocacy in her dealings with the Family Court would have been helpful. Megan's powerlessness was a consequence of her ex-partner, due to his gender, being viewed as more credible than she was by the Family Court and this favouring of the father by the Family Court Judge was an indication of hegemonic masculinity.

\section{Hegemonic masculinity}

The link between hegemonic masculinity and violence towards women has been identified in the literature (Pease, 2016). Hegemonic masculinity is based on the shared domination of men over women (Connell \& Messerschmidt, 2005) and is the dominant construction of masculinity, the version which is considered natural (Campbell, Bell, \& Finney, 2006; Connell, 2002) in a particular place at a particular point in time. In this study, the version of manhood considered natural was that of the hard man, someone who drinks heavily, works hard, does not express feelings and dominates women and children.

Manhood has been described as a precarious social status (Bosson, Vandello, Burnaford, Weaver, \& Wasti, 2009), which can be lost and needs to be reinforced by demonstrations of manhood which may be aggressive or violent (Vandello, Bosson, Cohen, Burnaford, \& Weaver, 2008). Manhood is a social construction (Bosson et al., 2009; Vandello et al., 2008), that is, who is considered to be masculine in a rural community may be different from what an ideal man is considered to be in a highly urban community such as Auckland. Masculinity intersects with other aspects of social life (Campbell et al., 2006) and, for rural men, masculinity can be enacted through work and recreation, including sport.

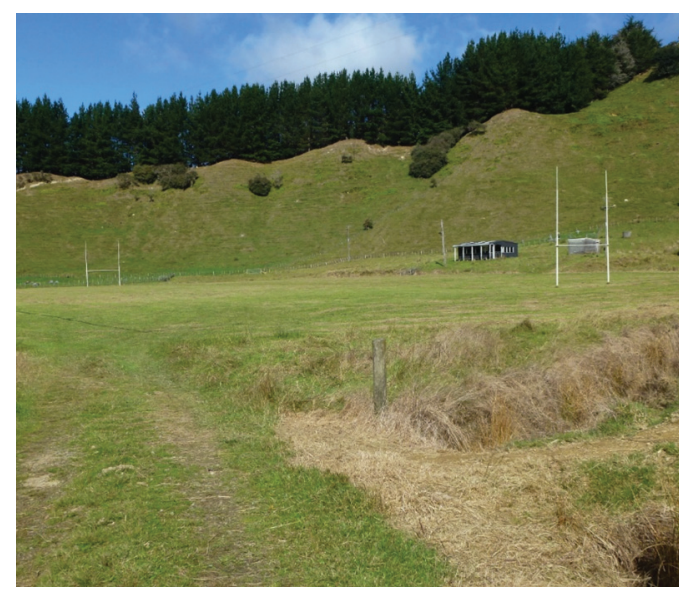


Above is a photograph of a rugby field which is in the study area. Rugby (union) has been noted as being a site where the dominant discourse of masculinity is enacted (Pringle, 2002). In this study district, the construct of an ideal man was shaped by the workplace and rugby. Because masculinity can be precarious, public displays of manliness, such as playing rugby union, can be used to reassert or defend manhood (Vandello et al., 2008). These ideas of rural masculinity can overtake "other more gentle ways of being male" (Pringle, 2002, p. 61).

Participants in this study talked about hegemonic masculinity (using the phrase "hard man") and the patriarchal power their partners had. The women supported their partners in their role as patriarch and it was accepted as a natural state of affairs. These findings are in keeping with an earlier ethnographic study of masculinity in small town New Zealand where the patriarchal power of men was noted as the norm and it was observed that young men were legitimised in the community whereas young women were not (Campbell et al., 2006).

Ironically, the notion of patriarchy could be enacted to protect women and children who were seen as vulnerable. Kelly talked about this in relation to another participant, Michelle, and her safety from her ex-partner. Kelly described her brother taking on the role as head of the family and protector, an example of patriarchy:

Kelly: I got my brother involved and because my brother is the next biggest person in line in the family, he told Michelle that he would assure her that if any major repercussions happened to her that he'd protect her - and that we were doing the right thing. He's quite bit younger than me. He's seven years younger than me, so he didn't see a lot [of family violence], but he's over six foot four. He's played for the [names Rugby League club] and he's a big guy and he's sees himself as the protector of the family, I suppose you'd say - even though he's my little brother.
In Kelly's excerpt, she mentions that her brother had played professional rugby league which meant that he fitted the hard man image in a rural community as he was physically able, tough and successful and hence he was viewed as personally powerful. Kelly's brother acted in a traditional patriarchal role as the leader of a family system (Bryson, 1992) and was a controlling and protective figure in an extended family. Masculinist protection has been considered benign and chivalrous but it masks hierarchal power. The subordination of women is a consequence of being protected (Young, 2003). While Michelle may have appreciated this protection and support her protection reinforced her powerlessness as a woman.

\section{Experiences of Intimate partner violence}

When participants in this study talked about intimate partner violence it was clear their experiences were affected by their rural location. One aspect of rural intimate partner violence is the use of geographic isolation to reinforce control. International research has identified that geographic isolation can be used as a form of entrapment by the perpetrators of intimate partner violence (Edwards et al., 2014; Faber \& Miller-Cribbs, 2014; Little, 2017; Mason, 2012; Wendt, 2009; Wendt et al., 2017). By removing their partner from social support and geographically isolating them, perpetrators are able to have more control. In a recent South Australian study into rural and remote women's help seeking when experiencing intimate partner violence it was identified that part of the pattern of abuse experienced by women who lived on remote properties was sustained physical isolation (Wendt et al., 2017). Women in both the Australian study and this research described being deterred from leaving their relationships due the distance needed to travel to seek help, such as in Michelle's story below. Physical distance and lack of access to transport other than the vehicle belonging to her partner, Murray, made it difficult for Michelle to 
leave the relationship. She talked about her experience of intimate partner violence from when she met Murray as a teenager until she left him when she was 32 .

Michelle: Before we went to live out the back we lived closer to town. We were on the dole-Murray was 25, I was 15. Murray was hiding from society cos he got worse and he treated us worse and it was his way of still being able to do it without anyone knowing - cos he'd go into town without me. Not only that, he put that much fear in me. He said he was going to kill my kids [also Murray's children], so you just think - you can't, because you've already tried [to leave the relationship]. He said he'd kill me, all of us, next time. So you're too scared to try - that was until I was starving - when it got that bad and there was no food. There was no way I was gonna eat any food, because my kids needed it, so yeah, I took off - I hadn't eaten for five months. As long as I was drinking coffee and the coffee, because I didn't have time for the coffee - I still do it - I sip coffee. I would spend four hours on a coffee, just sip it all day. I had no time for myself. He was just bellowing orders. It was a nightmare, no break. There was one hour a night, because he was addicted to morphine too, so he didn't sleep well at night. It was a fucken nightmare. We had no water out there, so shit, I'd have to go down and get water from the [a public source]. I don't know if I was allowed to - I just did.

Lesley: Did you take down water bottles and fill them up?

Michelle: Two, two litres and that would only fill one flush of the toilet, so I'd be doing that all the time. We were not far from the tap. I was just trying to make anything out of nothing. My kids do not love Sizzlers. The Food Bank would give you flour and stuff, so I'd make cakes and whatever that was in there I'd make use of. We had a lot of eggs on toast and Sizzlers. He'd get four ice-creams and we weren't allowed to touch them. He'd always threatened me. I'd come straight out of my mum's womb pretty much and to him and he brainwashed me ... he just totally brainwashed me and this is how life is - no-one cares about you. I had to plan for years how to get out, escape, with doing it properly. I had a bag hidden with survival stuff and my kids' photos, because he never left me - he locked the kids in the room. People don't realise that there's so many people stuck out in the middle of nowhere and you're not allowed a TV. You were 15 and now you're 32 and you've never been allowed to talk to anyone - how are you meant to think in your head what to do. The fact that I could have got out a long time ago and my son wouldn't have been damaged so bad - my kids wouldn't have been damaged so bad if I had seen a second on TV or a second in the hospital.... Like something telling me that I could get out and there's a way.

Within Michelle's story, the intersection of her age (15 when she met her partner), gender, poverty, lack of transport and isolation left her in a position of powerlessness. For social workers in rural communities the need to be aware of geographic isolation, particularly where there is no transport, is underscored by Michelle's story. Solutions which may be applicable in an urban context would not work for Michelle, for example, where Michelle lived meant that it would take approximately an hour for emergency services to reach her if she contacted them. Exploring other options to access help in a crisis would be useful if a social worker was working with Michelle, such as identifying a safe place for her to get to which was within walking distance of her home, as well as exploring potential transport options for her to get to town to seek further support.

Michelle overcame her powerlessness despite the danger and left Murray by walking over paddocks during the night until she could summon help. The violence 
has had long term consequences for Michelle and her children. Michelle endures the effects of a head injury and her eldest son suffers from depression as a result of being targeted by his father, as a child, for abuse and ridicule. Michelle's son was challenged based on his gender, for not being hyper-masculine (a hard man) like his father. Michelle's story demonstrated how patriarchy gets acted out. Her partner took the idea of the man as head of the family to the extreme using male privilege. He did not allow Michelle to speak to anyone outside the family and took complete control of the family system, which is an example of patriarchy (Millett, 1971). Michelle's expartner used violence and threats of violence in order to assert his power and dominance over her and their children

Kelly, who grew up in a family with Murray, Michelle's ex-partner, described why she did not identify Michelle's relationship as abusive and how she had lived in relationships where there was also intimate partner violence.

Kelly: I didn't know what was going on. I used to go out there every now and again, but on the surface everything looked okay. I didn't recognise it, cos I've grown up with it. My Dad was quite abusive and my grandfather was abusive. To me that was normal and I got in those relationships too. I haven't been in one of those for quite a long time; breaking that cycle. I think I just always met up with men that were like Murray and my father - those type of men - because that's what I was used to, I think, growing up. They seemed like real men, nice guys seemed like...yeah. People were scared of them and they had a reputation. Even my brother struggles with that reputation of - he's a family man and he's got kids but people still see him as "the man". So he's got the soft side of Mum, but he's still gotta try and hold that reputation of being a bit of a hard guy. It's a bit conflictual with him at times. But with me I'm just, nah, I'm stopping this now.
We've broken that cycle of violence and child abuse within my generation. We've stopped it, cos we recognise that we don't want it to continue.

Kelly had grown up in a family system where being a man meant being violent. It is as she matured that Kelly had started to question the construction of masculinity which she grew up with. As a result, Kelly, along with her brother and Michelle, were trying to change the cycle of intimate partner violence.

Lisa, another participant, was living in a violent relationship at the time of interview. She described her relationship where violence and control were prevailing factors dominating daily life. As with Michelle's story, drug taking was a feature of the relationship Lisa had with her partner and drugs were used by him to maintain control over her. Substance abuse was part of the complex nature of intimate partner violence for both of them, where addictions, poverty, rurality and violence intersect. Substance abuse, as well as poverty, are risk factors for intimate partner violence (Crichton-Hill \& Taylor, 2013; Edwards et al., 2014). The link between substance abuse, rurality, poverty and intimate partner violence has been identified in earlier studies in South Carolina in the USA (Faber \& Miller-Cribbs, 2014) and in central Queensland, Australia (Mason, 2012).

Lisa: He's [partner] very loyal like that. He would never ever cheat on me. When he's being nice, he's the most wonderful person ever. He's the perfect man; talks about me like I'm his everything. But then it's like a switch from Jekyll to Hyde. $\mathrm{He}^{\prime}$ s the most beautiful, loving man I've ever met, and then he's the most hateful, spiteful, disgusting man I've ever met as well, and it's hard to say that about the same person. I don't get it. I just don't get how someone could be like that. I understand everyone has a bad day sometimes and can be in a shit, but not to that extreme. That's another thing, I don't 
know which one is real. It's usually when he's got no pot. He's into other drugs as well, but he's usually alright without other drugs. But when he's got no potpot is the big thing and it's ridiculous. I know there are thousands of people that do - over pot. Probably the worst thing that's happened to my life is getting hooked on that shit. I used to dabble with drugs and just be a social drug taker, but I always swore I would never ever try heroin because I'd be scared I'd like it too much and I've seen all the movies with heroin addicts. And then when I met him, I knew he was into his drugs, but he offered and I tried it and I liked it; and he kept offering the next day and the next day and I finally said to him, "What is this stuff?" and he said, "Oh, it's synthetic heroin", and, yeah, I was hooked. And to this day, I think, if you loved someone as much as you say you do, why would you give them something that's so horribly addictive? That's the last thing I'd give someone I claimed to love.

Lisa's experience of addiction (she is on the methadone programme) which had been encouraged by her partner kept her stuck in a relationship with him. Lisa had lived on a benefit for some time and would like to move off it but had limited employment opportunities in the study district. Being poor, living in a rural community and having issues with her mental health made it difficult for Lisa to leave her abusive partner. Lisa's partner used his male privilege to control her. Embedded within Lisa's story, as for Kelly, Michelle and Sally, was the role of patriarchy and the acceptance of hegemonic masculinity, in which violence towards women and children and other men was accepted.

\section{Implications for social workers}

A nuanced understanding of patriarchy is important for all social workers. By identifying patriarchal behaviour and systems practitioners can work with their client/s to understand the link from their personal experiences to the political context. During the second wave of feminism, consciousness-raising groups were established to encourage women to talk about their personal problems. Women discovered their personal troubles were shared and that through collective action they could seek political solutions. By understanding personal experiences, hidden from public view, individual oppression was reframed as political/structural domination (Letherby, 2003).

Social workers in rural communities can use consciousness raising in work with women who have experienced intimate partner violence. When women understand their experience is not as a result of their individual failing but part of a wider system of patriarchy they are freed from blame. Social workers in rural communities need to be aware of the way in which traditional notions of masculinity and male privilege is used in intimate partner violence. Rural social workers also have a responsibility to challenge traditional gender norms which contribute to, and support, intimate partner violence.

\section{Limitations of study}

Using a thematic approach to data analysis was a limitation of the study. The focus was on what was said by participants rather than how they talked about their experiences. This focus enabled the research to be used to inform social policy as analysing what was said by participants allowed for a collectivising of experiences.

The choice of one geographic area is a limitation as the study reflects the place where the study was undertaken. Further research in other rural communities would widen understanding of rural intimate partner violence in Aotearoa New Zealand as would research using a Kaupapa Māori approach focused on the tangata whenua experience. As this study was qualitative the data gathered for this study are not generalisable and need to be read as being about that area and these participants, it is contextualised, and readers can determine 
how relevant it is to the context in which they live and work (Elliott, 2005). The study is exploratory and the findings here could be used to construct a broader quantitative study looking at multiple rural areas.

\section{Conclusion}

Being aware of the nuances of gender and power is important in social work practice. When working with people from rural communities, social workers need to be alert to how traditional gender roles, patriarchy and hegemonic masculinity impact on rural women and make them vulnerable to intimate partner violence.

This study, in relation to the experience of violence and rural women, shares similarities with Australian research which identified that, while there are similarities between violence in rural and urban locations there are some different factors which shape violence in a rural context (Wendt \& Zannettino, 2015). Geographic isolation, traditional gender roles, hegemonic masculinity, lack of access to transport and substance abuse were aspects of the stories shared by rural women in this study about their experience of intimate partner violence. Social workers in rural communities have to be aware of the way gender has been socially constructed and be creative in finding solutions to rural problems. In these stories, the solutions to intimate partner violence in an urban context were not useful as they did not take into account the impact of geographic isolation, distance from services, transport issues and the way in which rural culture supports intimate partner violence.

\section{References}

Averett, P. (2009). The search for wonder women: An autoethnography of feminist identity. Affilia: Journal of Women and Social Work, 24 (4). 360-368. doi:10.1177/0886109909343569

Babbie, E. (2017). The basics of social research (7th ed.). Melbourne, VIC: Cengage Learning.

Bosson, J. K., Vandello, J. A., Burnaford, R. M., Weaver J. R., \& Wasti, S. A. (2009). Precarious manhood and displays of physical aggression. Society for Personality and Social Psychology, 35(2). doi:10.1177/0146167208331161
Bryson, V. (1992). Feminist political theory: An introduction. Hampshire, UK: MacMillan.

Campbell, H. (2006). Real men, real locals, and real workers: Realizing masculinity in small-town New Zealand. In H. Campbell, M. M. Bell, \& M. Finney (Eds.). Country boys: Masculinity and rural life (pp. 87-103). University Park, PA: Pennsylvania State University Press.

Campbell, H., Bell, M. M., \& Finney, M. (2006). Masculinity and rural life: An introduction. In H. Campbell, M. M. Bell, \& M. Finney (Eds.). Country boys: Masculinity and rural life (pp. 1-22). University Park, PA: Pennsylvania State University Press.

Connell, R. W. (1995). Masculinities (2nd ed.). Cambridge, UK: Polity.

Connell, R. W. (2002). Masculinities and globalisation. In H. Worth, A. Paris, \& L. Allen (Eds.), The life of Brian: Masculinities, sexualities and health in New Zealand (pp. 27-42). Dunedin, New Zealand: University of Otago Press.

Connell, R. W., \& Messerschmidt, J. W. (2005). Hegemonic masculinity: Rethinking the concept. Gender and Society, 19(6), 829-859. doi:10.1177/0891243205278639

Crabtree, B. F., \& Miller, W. L. (1992). A template approach to text analysis: Developing and using codebooks. In B. F. Crabtree \& W. L. Miller (Eds.), Doing qualitative research (pp. 93-109). Newbury Park, London: Sage.

Crichton-Hill, Y., \& Taylor, A. (2013). Intimate partner violence. In A. Taylor \& M. Connolly (Eds.), Understanding violence: Context and practice in the human services (pp. 102-117). Christchurch, NZ: Canterbury University Press.

Davidson, C., \& Tolich, M. (2003). Competing traditions. In C. Davidson \& M. Tolich (Eds.), Social science research in New Zealand: Many paths to understanding (pp. 23-38). Auckland, NZ: Pearson.

Edwards, K. M., Mattingly, J. J., Dixon, K. J., \& Banyard, V. L. (2014). Community matters: Intimate partner violence among rural young adults. American Journal of Community Psychology, 53, 198-207. doi:10.1007/s10464-014-9633-7

Elliott, J. (2005). Using narrative in social research: Qualitative and quantitative approaches. London: Sage. doi:10.4135/9780857020246.n2

Faber, N., \& Miller-Cribbs, J. E. (2014). Violence in the lives of rural, southern, and poor white women. Violence Against Women, 20(5), 517-538. doi:10.1177/1077801214535104

Guest, G., MacQueen, K. M., \& Namey, E. E. (2012). Applied thematic analysis. Thousand Oaks: Sage. doi:10.4135/9781483384436.n3

Hall-Sanchez, A. (2016). Intimate partner violence against rural women: The current and future state of feminist empirical and theoretical contributions. Sociology Compass, 10(4), 272-283. doi:10.1111/soc4.12358

hooks, b. (1982). Ain't I a woman: Black women and feminism. London, UK: Pluto Press.

Jewkes, R., Morrell, R., Hearn, J., Lundqvist, E., Blackbeard, D., Lindegger, G.,... Gottzén, L. (2015). Hegemonic masculinity: Combining theory and practice in gender interventions. Culture, Health \& Sexuality, 17(2), 112-127. doi:10.1080/13691058.2015.1085094 
Letherby, G. (2003). Feminist research in theory and practice. Buckingham, UK: Open University Press.

Little, J. (2017). Understanding domestic violence in rural spaces: A research agenda. Progress in Human Geography, 41(4), 472-488. doi:10.1177/0309132516645960

Mammen, S., \& Sano, Y. (2012). Gaining access to economically marginalized rural populations: Lessons learned from nonprobability sampling. Rural Sociology, 77(3), 462-482. doi:10.1111/j.1549-0831.2012.00083.x

Mason, R. (2012). Dealing with violence: Families living in rural settlements. In J. Maidment \& U. Bay (Eds.), Social work in rural Australia: Enabling practice (pp. 119-132). Sydney, NSW: Allen \& Unwin.

May, T. (2011). Social research: Issues, methods and process (4th ed.). Buckingham, England: Open University Press.

Millett, K. (1971). Sexual politics. London, Great Britain: Virago.

New Zealand Family Violence Clearinghouse. (2017). Supplementary data: Regional data by police district. Retrieved from https://nzfvc.org.nz/data-summaries/ supplementary-data-regional-data-police-district

Pease, B. (2016). Interrogating privilege and complicity in the oppression of others. In B. Pease, S. Goldingay, N. Hosken, \& S. Nipperess (Eds.), Doing critical social work: Transformative practices for social justice (pp. 89-103). Sydney, NSW: Allen \& Unwin.

Pringle, R. (2002). Living the contradictions: A Foucauldian examination of my youthful rugby experiences. In H. Worth, A. Paris, \& L. Allen (Eds.), The life of Brian: Masculinities, sexualities and health in New Zealand (pp. 57-72). Dunedin, New Zealand: University of Otago Press.

Rennison, C. M., \& DeKeseredy, W. S. (2017). Situational contexts of rural violence: A comparison of male and female perpetration. Journal of Contemporary Criminal Justice, 33(2), 189-206. doi:10.1177/1043986216688813

Sadler, G. R., Lee, H-C., Lim, R. S-H., \& Fullerton, J. (2010). Recruitment of hard-to-reach population subgroups via adaptations of the snowball sampling strategy. Nursing and Health Sciences, 12, 369-374. doi:10.1111/j.14422018.2010/00541.x

Statistics New Zealand (n.d.). 2013 QuickStats about a place: Stratford District. Retrieved from http://www.stats. govt.nz/Census/2013-census/profile-and-summaryreports/quickstats-about-a-place.aspx?request value $=14148 \&$ tabname $=$

Young, I. M. (2003). Feminist reactions to the contemporary security regime. Hypotia, 18(1), 223-231.

Vandello, J. A., Bosson, J. K., Cohen, D., Burnaford, R. M., \& Weaver, J. R. (2008). Precarious manhood. Society for Personality and Social Psychology, 95(6), 1325-1339. doi:10.1037/a0012453

Wendt, S. (2009). Constructions of local culture and impacts on domestic violence in an Australian rural community. Journal of Rural Studies, 25, 175-184. doi:10.1016/j. jrurstud.2008.11.001

Wendt, S., Chung, D., Elder, A., Hendrick, A., \& Hartwig, A. (2017). Seeking help for domestic and family violence: Exploring regional, rural, and remote women's coping experiences: Key findings and future directions. Compass: Research to Policy and Practice, 6. Retrieved from https://www.anrows.org.au/wpcontent/uploads/2019/02/RP.14.04_Rural_Compass_ FINAL_1709-1.pdf

Wendt, S., \& Zannettino, L. (2015). Domestic violence in diverse contexts: A re-examination of gender [e-book]. London, UK: Routledge.

Whelehan, I. (1995). Modern feminist thought: From the second wave to "post-feminism". New York, NY: New York University Press.

Women's Refuge New Zealand. (2015). Statistical report. Women's Refuge Annual Report 2014-2015. Retrieved from https://womensrefuge.org.nz/wp-content/ uploads/2015/11/Domestic-violence-statistics-NZ.pdf 